\title{
Use of a MEMS-Based TEM Heating Stage to Characterize Carbide Precipitation in Alloy 690
}

\author{
Jonas K. Heuer ${ }^{1}$ \\ 1. Naval Nuclear Laboratory, Plant Materials and Laboratory Services, West Mifflin, PA, USA.
}

Heating stages have been used for several years to study a number of dynamic metallurgical phenomena in metals and alloys directly in electron microscopes to help visualize processes and determine mechanisms associated with exposure to elevated temperatures. Some applicable phenomena that can be studied with this in situ technique include phase transformations, precipitate formation, grain growth, quenching behavior, and recovery of deformation structures. This study provides an initial evaluation of the use of a heating stage based on Micro-Electrical-Mechanical Systems (MEMS) technology. Unlike traditional furnace-based heating stages for Transmission Electron Microscopes (TEMs), MEMS-based heating stages offer higher operating temperatures, provide faster heating/cooling rates, and have reduced thermal drift.

An Alloy 690 (A690) specimen was chosen to demonstrate the capabilities of this heating stage. A690 is an austenitic nickel-based alloy commonly used as a steam generator tubing material in pressurized water reactors due to its excellent resistance to intergranular stress corrosion cracking in a broad range of aqueous environments [1-3]. The A690 material used in this examination originated from an inprocess sample of heavily cold-worked material prior to final annealing. Therefore, the material is expected to have a heavily deformed microstructure and contain a matrix that is supersaturated with carbon based on being solution-annealed prior to cold working. This microstructure makes it a good specimen to evaluate the heating stage because it allows a number of temperature-based phenomena to be examined. At lower temperatures $\left(\leq 800^{\circ} \mathrm{C}\right)$, these phenomena include recovery of the deformation structure, precipitation of carbides from the supersaturated matrix, and recrystallization and growth of the matrix grains. At higher temperatures $\left(\sim 1100^{\circ} \mathrm{C}\right)$, dissolution of the precipitated carbides is expected during solution annealing with potential re-precipitation at sufficiently-slow cooling rates.

In situ thermal examinations were performed using a Protochips Fusion heating stage in an FEI Tecnai F20 TEM. This TEM is equipped with a high angle annular dark field detector, a secondary electron detector, and an Oxford Instruments X-Max100-TLE windowless silicon drift detector for energy dispersive X-ray spectroscopy. Specimens were prepared for the heating studies using a two-step process. The first step involved preparing conventional TEM foils by electropolishing $3 \mathrm{~mm}$ discs at $-32^{\circ} \mathrm{C}$ and $14-16 \mathrm{~V}$ in an electrolyte composed of $20 \%$ perchloric acid and $80 \%$ methanol, and the second step involved extracting $40 \times 40 \mu \mathrm{m}$ regions of electron-transparent material around the central perforations in these foils using a Focused Ion Beam (FIB) instrument for mounting onto the heating membranes of MEMS substrates. Each sample was heated from $20^{\circ} \mathrm{C}$ up to $800-900^{\circ} \mathrm{C}$ at rates of $1-$ $5^{\circ} \mathrm{C} / \mathrm{sec}$. Ramping was paused at intervals of $100-300^{\circ} \mathrm{C}$ where the temperature was held constant for 510 minutes so that images could be acquired of the microstructure at each hold temperature. After reaching the ultimate ramping temperature, each sample was cooled from $800-900^{\circ} \mathrm{C}$ down to $20^{\circ} \mathrm{C}$ at a rate of $7-8^{\circ} \mathrm{C} / \mathrm{sec}$, and additional imaging and analysis was subsequently performed at room temperature. The entire heating trial on each sample lasted approximately 45 minutes. 
Initial examinations before heating revealed that the cold-worked A690 matrix has a fairly uniform structure with few second-phase precipitates present (Figure 1). The grain structure is larger than the size of the extracted FIB foils, and only a single grain boundary was captured among the foils used for heating examinations. Prior to heating, scanning-transmission imaging confirms that the A690 grains contain defect structures consistent with cold-worked material. Upon heating, discrete chromium carbides are observed to form in the matrix. Carbide formation in the matrix is first noted at $600^{\circ} \mathrm{C}$, and growth of these carbides to approximately $100-200 \mathrm{~nm}$ in size is clearly apparent at $800^{\circ} \mathrm{C}$. Larger chromium carbides are also observed to form along the grain boundary over this same temperature range; at $600^{\circ} \mathrm{C}$, discrete carbides are noted to form along this boundary, and these discrete carbides grow to form a single long continuous carbide several microns in length at $800^{\circ} \mathrm{C}$. Upon cooling from $800^{\circ} \mathrm{C}$ to $20^{\circ} \mathrm{C}$, precipitation of finer carbides is observed. These finer carbides are generally less than $50 \mathrm{~nm}$ in size, and they precipitate both within the matrix and also at grain boundaries.

In summary, the capabilities of a MEMS-based TEM heating stage were demonstrated on a cold-worked A690 sample. Dynamic temperature-dependent phenomena that were successfully observed include formation of chromium carbides at $600^{\circ} \mathrm{C}$ in both the material matrix and at grain boundaries, growth and coalescence of discrete intergranular carbides into long continuous carbides along grain boundaries at $800^{\circ} \mathrm{C}$, and precipitation of fine carbides upon cooling from $800^{\circ} \mathrm{C}$ to $20^{\circ} \mathrm{C}$. Finally, it must be noted that these initial heating trials were limited to temperatures $\leq 900^{\circ} \mathrm{C}$ which precluded in situ solution annealing studies of the dissolution of the precipitated carbides.

\section{References:}

[1] JJ Kai et al, Metallurgical Transactions A 20A (1989) 2057.

[2] S Xia et al, Metallurgical and Materials Transactions A 40A (2009) 3016.

[3] TM Angeliu and GS Was, Metallurgical Transactions A 21A (1990) 2097.

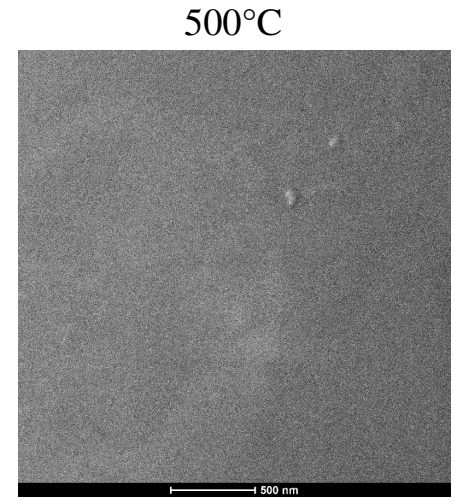

cold-worked matrix

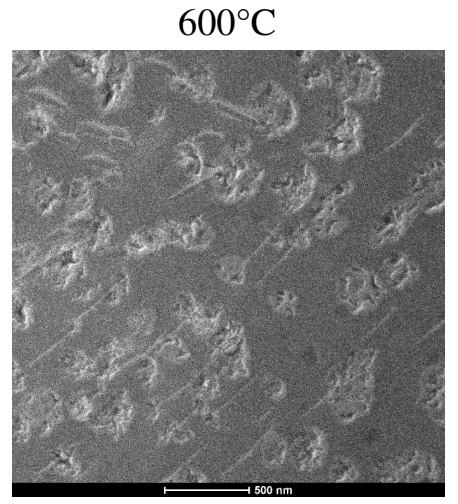

carbide formation

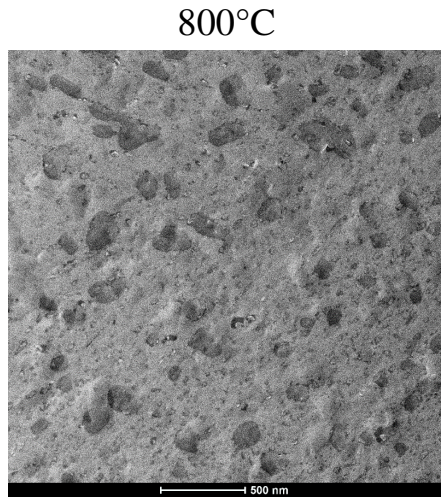

carbide growth

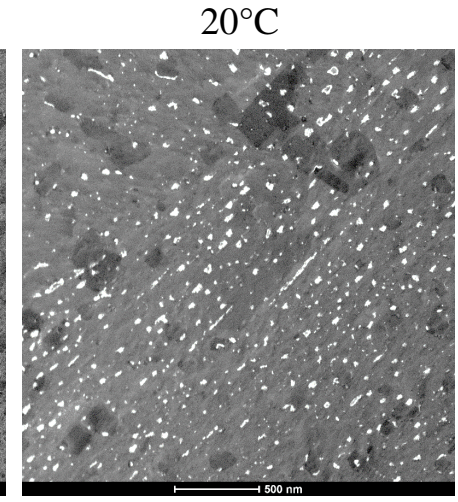

fine carbide precipitation

Figure 1. Secondary electron images showing the formation of chromium carbides in a cold-worked A690 matrix supersaturated with carbon. All images originate from the same TEM foil. At $600^{\circ} \mathrm{C}$, carbides begin to form in the matrix, and at $800^{\circ} \mathrm{C}$ growth of these carbides is apparent. Upon quenching to $20^{\circ} \mathrm{C}$, precipitation of finer carbides is also observed. 